\title{
Identidade, Marca e Consumo: Construções Simbólicas na Tessitura da Cultura
}

\author{
Identity, Brand and Consumption: \\ Symbolic Constructions in Culture's Texture
}

por Amanda Queiroz Campos,

Álvaro Roberto Dias e Richard Perassi

\section{RESUMO}

0 presente artigo tem o objetivo de discutir a marca enquanto construção simbólica, inserida competitivamente no contexto cultural de consumo. A identidade de uma marca depende da dimensão sensível de seus usuários em função de suas experiências. Cabe ao designer gráfico capitalizar essas experiências através de uma comunicação visual, aqui representada pela identidade visual, criando um diferencial estratégico da marca através de conceitos simbólicos. Assim, a identidade pode ser percebida através de linguagens e da manipulação de signos. Também nas histórias construídas pelo design aparecem as significações já existentes na cultura. Cada composição gráfica para expressão da marca é uma composição de fragmentos de dois códigos: um código genético e um código cultural.

Palavras-chave marca; consumo; cultura

\section{ABSTRACT}

This present paper aims to argue the brands as symbolic constructions competitively inserted in the consumption's cultural context. A brand's identity depends on the sensible dimension related to their users' experiences. It is the graphic designer's job to capitalize those experiences through visual communication, here represented by the visual identity, in order to create a strategic advantage of the brand by the symbolic concepts. Therefore the identity can be perceived through languages and signs manipulation. Also, in the stories created by design one may notice the significations already established in the culture. Each graphic composition to the expression of the brand is composed by fragments of two codes: a genetic code and a cultural code.

Keywords brand; consumption; culture 


\section{Introdução}

Este texto é produto dos estudos realizados nos cursos de mestrado em Design e Expressão Gráfica (Pós-Design/UFSC) e doutorado em Engenharia e Gestão do Conhecimento (EGC/UFSC) tratando do tema "sintaxe da informação gráfico-visual". 0 tema proposto também é desenvolvido na linha de pesquisa "Gestão estratégica do design gráfico", no contexto do grupo de pesquisa SIGM0: Significação da Marca, Informação e Comunicação Organizacional (UFSC/CNPQ).

0 presente artigo discute a marca enquanto uma construção simbólica feita pelo designer ao projetar uma identidade visual. Pretende-se refletir, através de uma abordagem teórica, no que consiste criar um diferencial para que a marca além de ser vista torne-se participante de uma estratégia competitiva de consumo. 0 que não é visto, o que não é manifesto, não pode ser interpretado e, portanto, não pode concorrer à construção da identidade manifesta.

0 significado de marca inserida no contexto cultural vai além de um simples nome ou algumas amostras de sua comunicação. São os conceitos simbólicos que acabam fazendo sentido ao consumidor na medida em que se atribui à simbolização o aspecto abstrato da relação do homem com o mundo. Ao escolhermos um objeto em detrimento de outro, escolhemos as significações específicas que um deles carrega.

A identidade manifesta de uma marca é totalmente dependente da dimensão sensível com a qual interagem os destinatários. As possibilidades que o usuário encontra no mundo o fazem um local ideal na busca de vivencias e experiências múltiplas. Para tanto, há de se considerar os recursos visuais do design para um indivíduo com particularidades de significação e desenvolver uma representação gráfica na ótica da comunicação da marca. Cabe ao designer o papel de organizador de mensagens, ou de narrador de contos, o que implica em um potencial estratégico mercadológico para o design enquanto competência para gestão de projetos, processos e marcas.

\section{Identidade da marca comercial}

Uma das grandes estratégias das marcas comerciais hoje é a busca de um diferencial para atingir e manter os seus consumidores, buscando criar um reconhecimento e uma identificação. A marca quer ser percebida. Um modo de aperfeiçoar a percepção dos sinais e valores emitidos pela marca parte do pressuposto que aspectos estético-expressivos e semântico-simbólicos da identidade deve ser considerado e controlado nos processos de gestão de serviços e comunicação da marca corporativa.

A ADG, Associação dos Designers Gráficos, define identidade visual como o conjunto sistematizado de elementos gráficos que identificam visualmente uma empresa, uma instituição, um produto ou um evento, personalizando-os. Uma das funções 
dos sistemas de identidade visual é agregar à imagem corporativa determinados conceitos que a valorizem junto ao seu público-alvo (ADG, 2012).

Do mesmo modo, um logotipo, um símbolo gráfico, uma tipografia, um conjunto de cores, são as estruturas e traços que remetem a um caráter ou imagem pretendida, ou seja, objetos percebidos pelo olhar. Um dos elementos mais comuns da identidade visual é a marca, definida como nome, símbolo gráfico ou logotipo (e/ou a combinação desses elementos), utilizados para identificar produtos ou serviços de um fornecedor/vendedor e diferenciá-los dos demais concorrentes.

A comunicação visual de marcas implica a utilização de uma identidade visual. A identidade visual é a forma como uma empresa é identificada visualmente. Normalmente a identidade visual compreende um logotipo composto por símbolo e nome, cores institucionais, fontes institucionais, grafismos, mascotes e adaptações de um ou mais dos elementos já citados.

No campo do design, em geral, criar uma identidade visual significa desenvolver um conjunto de elementos gráficos para que estes construam visualmente a personalidade de um nome, ideia, produto ou serviço. Para o design, de uma forma geral, qualquer coisa possui uma identidade visual, e esta identidade é aquilo que singulariza visualmente um dado objeto; o que o diferencia dos demais por seus elementos visuais. Assim, para o design, qualquer coisa que possa ser identificada visualmente possui uma identidade visual (identificação e reconhecimento de identidade). (DIAS, 2006, p.14)

A identidade visual ultrapassa os sentidos de representação simbólica da organização, no sentido em que faz interface com o público e transmite valores e atributos da organização. Assim, a identidade visual é entendida como estratégia, visto que ela é adotada de forma consciente pelas empresas que se empenham em adequar as questões técnicas referentes ao produto e serviço que oferecem com os desejos dos seus consumidores e as configurações do mercado.

A construção de uma marca não é uma tarefa fácil. Marcas fortes são construídas em ativos ao longo do tempo, às vezes, tempo demais para a liquidez da modernidade e velocidade e constância de mudanças em si mesmas. Usualmente ligado à palavra fashion, o termo branding surge como sinônimo de criação e gestão de marca, tendo a palavra inglesa brand o significado de conjunto ou sistema conceitual da marca organizacional.

A área de Branding trata de métodos e processos de prospeç̧ão da imagem da marca junto a diversos seguimentos. Além disso, coordena a construção e o desenvolvimento da marca e da organização e gerencia as expressões e a comunicação da identidade de marca. Os objetivos do Branding visam minimizar a diversificação perniciosa das imagens da marca e consolidar a identidade na mente de todas as pessoas que, direta ou indiretamente, vivenciam as expressões da organização. (PERASSI, 2010. p.7-8) 
A função do designer gráfico e do publicitário neste cenário é criar um diferencial para que a marca seja vista, participando de uma estratégia competitiva. Assim, esses profissionais devem elaborar peças gráficas de comunicação que não apenas expressem a identidade da marca de modo integrado e com unidade. Também é necessário que eles inovem a imagem da marca e, consequentemente, o seu reconhecimento no mercado, ao utilizar as premissas de branding como ferramentas que permitirão uma visão estratégica da marca para a gestão da identidade e comunicação da empresa.

As ferramentas estratégicas de construção da imagem da marca implicam de modo positivo na sua transmissão. Normalmente, as marcas fortes possuem uma ideia principal: um slogan, uma cor, um logotipo e uma série de histórias associadas a uma determinada entidade. As marcas devem transmitir à mente das pessoas uma ideia, um conceito, um posicionamento. Por isso, as mensagens visuais devem aparecer e comunicar de forma integrada e direcionada, propiciando a compreensão e reconhecimento de modo unificado e constante e levando os consumidores a reconhecer a marca com maior facilidade.

As expressões da identidade visual através da comunicação integrada de marca podem ser evidenciadas, por exemplo, no uso de uma combinação constante de cores, o que auxilia no reconhecimento da marca. Através da manipulação de elementos da expressão visual, organizam-se conceitos subjetivos, simbólicos, que refletem a identidade de uma marca.

\section{Simbolismos na comunicação da marca}

Randazzo (1997) concebe a marca como entidade física e perceptual, sendo que esse último aspecto implica na existência de um plano psicológico. 0 plano psicológico é dinâmico e maleável, caracteriza-se enquanto mitologia latente. Mitologia esta que abarca "a totalidade das percepções, crenças, experiências e sentimentos associados" (RANDAZZO, 1996, p. 23).

A identidade torna-se uma celebração móvel: formada e transformada continuamente em relação às formas pelas quais somos representados ou interpelados nos sistemas culturais que nos rodeiam (HALL, 1998, p. 13). Sendo assim, uma marca só passa a ser marca quando se torna identificável, ou seja, quando as pessoas a associam a outras coisas e outras situações. Uma marca, então, passa a ter uma história e interferir na maneira como as pessoas veem os produtos, ligando-os, definitivamente, à marca.

Para HALL (1998, p.11),

a identidade preenche o espaço entre o "interior" e o "exterior" entre 0 mundo pessoal e o mundo público. 0 fato de que projetamos a "nós próprios" nessas identidades culturais, ao mesmo tempo em que internalizamos seus significados e valores, tornando-os "parte de nós" contribui para alinhar nossos sentimentos subjetivos com os lugares objetivos que ocupamos no mundo social e cultural. A identidade, então, costura (ou, para 
usar uma metáfora médica, "sutura") o sujeito à estrutura. Estabiliza tanto os sujeitos quanto os mundos culturais que eles habitam, tornando ambos reciprocamente mais unificados e prediziveis.

Perassi (2011) propõe que a partir de uma compreensão filosófica pode-se conceituar a marca "como um sistema cultural aberto e interativo. Sendo a cultura de cada marca institucional ou comercial participante da cultura de mercado que, cada vez mais participa da cultura geral e amplia o contexto interativo de emergência e influência de cada marca particular" (PERASSI, 2011, p.1). Isso implica que o estudo para a criação e composição de signos gráficos, principalmente desenvolvidos para a comunicação de marcas envolve uma compreensão acerca da construção e composição de signos culturais, de modo a serem aplicados no processo de gerenciamento simbólico da marca.

São esses conceitos simbólicos que farão sentido aos consumidores. Os consumidores não compram um carro para levá-lo de um ponto a outro, ou um relógio para que the informem as horas. Também não usam uma roupa porque ela the cobre a nudez e nem bebem um uísque porque ele ajuda a relaxar. A cada escolha, opta-se pela a marca pela qual mais se sente atraído, conquistado.

A mitologia latente provém das experiências do consumidor com o produto, mas também da história, dos fatos, do folclore e das crenças que cercam o produto. "Muitas vezes a mitologia latente do produto desempenha um papel fundamental na formação das mitologias da marca. Informação, intuições e ideias oriundas da mitologia latente do produto são amiúde usadas na publicidade" (RANDAZZO, 1997, p. 30). Marcondes $(2003$, p. 53) compreende que, "assim como as sociedades de todos os tempos adotam preceitos sagrados, religiosos e políticos, o consumidor contemporâneo mantém, com suas marcas de preferência uma relação de crença também muito especial".

De uma maneira geral, atribui-se à simbolização o aspecto abstrato da relação do homem ao mundo, tornando-o capaz de "orientar-se em termos simbólicos". As regulações - como se fosse possível regular - necessárias para responder aos estímulos do meio e integrá-los tornar-se-iam então em uma forma de construção simbólica do universo, pois seria desta maneira que o homem se relacionaria com o mundo. Ele, então, construiria 0 universo através desta "função simbólica". Para o consumidor dos dias de hoje, as marcas funcionam como parâmetros abstratos de sua afirmação social. Como uma mitologia de mercado, um ritual de compra e adoração.

\section{Consumo simbólico}

I'm completely lost in the supermarket

I can no longer shop happily

I came here for that special offer

A guaranteed personality

(THE CLASH apUd SVENDSEN, 2010. p. 127) 
0 filósofo Svendsen (2010) faz uso de versos da banda britânica The Clash para introduzir o conceito de consumo em sua obra. A mensagem que a letra de Lost in the supermarket passa é bastante explícita. Diz respeito ao supermercado de estilos e de personalidades que configuram o mercado ocupado pelos produtos e pelas marcas na atualidade. Entretanto, não se pode negar a mudança de paradigma com a qual nos encontramos. Cada vez mais, consolida-se enquanto uma sociedade de consumo versus uma anterior sociedade de produção.

A principal condição do ser humano na pós-modernidade é a de ser consumidor. Como justificativa, fica evidente que se passa e crescentemente passar-se-á cada vez menos tempo de nossas vidas dedicando-se ao trabalho (De Masi, 2000). Produz-se por apenas um determinado período da vida; em contraposição, consome-se desde o instante em que se nasce até a morte. É tarefa impossível dar conta da complexidade e multiplicidade de padrões de consumo. Entretanto a busca por definições e clareamento de conceitos e práticas faz-se válida e imperativa para que se compreenda, ainda que de modo parcial ou superficial esse fenômeno que envolve todas as sociedades capitalistas.

Win Wenders (apud SVENDSEN, 2010) coloca que estamos cercados de imagens, a maior parte do tempo, essas imagens não visam informar algo construtivo, objetivam vender. A necessidade mais básica do ser humano é que as coisas signifiquem, ou seja, sejam dotadas de significado e transmitam mensagens. Assim como uma criança quer ouvir uma história antes de dormir, a necessidade da criança não reside na história em si, mas o ato de ouvir uma história contada pelos pais, que cria segurança e conforto. Ao atingir idade adulta, ainda necessita-se do conforto e segurança provenientes de quaisquer histórias que são fornecidas. A estrutura das histórias confere sentido, que de modo geral nossas vidas carecem.

A ideia de que a tarefa do consumo era apenas satisfazer necessidades já existentes é limitada. 0 consumo implica em processos de construção de identidade, além de configurar-se enquanto um tipo de entretenimento para a sociedade moderna e pós-moderna. A questão da formação ou desenvolvimento de uma identidade baseia-se principalmente no papel simbólico que o consumo desempenha.

Considerando as ideias de Schouten (1991), Miranda (2008, p. 37) ratifica que "uma das características que distingue os seres humanos das outras criaturas vivas é sua habilidade de identificar suas carências para procurar suprir as suas necessidades de auto-aperfeiçoamento". Isso ocorre, principalmente, através da relação direta com os conceitos e personalidade da marca.

0 consumo é campo privilegiado para a manutenção e cultivo do eu, visto que esse eu se constrói em interação com objetos diversos. 0 que parece paradoxal é o fato de que através do consumo de produtos de marca dotados de conteúdo impessoal e ofertas que buscam superar características particulares busca-se desenvolver uma identidade própria.

Mozotta (2011) entende que as pessoas se envolvem com as marcas do mesmo modo com que se relacionam com outras pessoas. Marcas e pessoas têm nomes, 
família, estilos e imagens. Ambas estão submetidas a diferentes ciclos de vida. "Conceituar uma marca por meio da personalização tornou-se um modo muito poderoso de construir a identidade da marca" (MOZOTTA, 2011, p.135). Através de ações de marca, produtos e serviços estão relacionados a uma categoria de valores particular.

"Como um último recurso, sem nada de coletivo a que recorrer, vamos em busca de grandes marcas na tentativa de nos individualizar. Por mais contraditório que seja, buscamos entidades extremamente abstratas e impessoais para mostrar quem somos como indivíduos únicos" (SVENDSEN, 2010. p. 137). De fato, os símbolos adquiridos por meio do consumo relatam algo do que se é. A personalidade das pessoas entra em jogo ao afirmar-se através da apropriação de objetos dotados de qualidades específicas.

Ao escolhermos um objeto em detrimento de outro, escolhemos as significações específicas que um deles carrega. A identificação sempre caracteriza uma demarcação dupla: positiva e negativa. 0 que se compra são as diferenças, diferenças marcadas pelo valor simbólico. A relação que a sociedade pós-industrial tem com 0 consumo e com os objetos é dada muito mais a nível simbólico do através do uso dos objetos. É interessante também observar que os símbolos-mercadorias, através de uma diversidade de relações e semelhanças, criam metáforas e analogias do próprio ser humano. Estes entrelaçamentos também se instauram no momento ao que se estabelecem outras conexões entre o eu mesmo e o outro. Essas trocas simbólicas dão-se através da mediação da cultura, espaço em que se legitima e constrói significados comuns.

\section{Comunicação das organizações e cultura de mercado}

“É difícil não se preocupar com as marcas na sociedade atual (...). Até mesmo os que afirmam que as marcas não são importantes para eles permitem que elas desempenhem um papel significativo quando avaliam um produto" (SVENDSEN, 2010. p. 144). Nesse sentido, pode-se apontar que o papel das comunicações visuais das organizações e das marcas não termina na produção e distribuição, mas sim no efeito que causa às pessoas. Cabe aqui deixar clara a influência do lado psicológico nesse processo, principalmente a partir de uma compreensão mais profunda acerca das características simbólicas do consumo e o cada vez mais notável mundo de encanto e sedução que as marcas visam criar para estabelecerem-se em um mercado marcado pela alta competitividade.

"No século XIX, a produção e o consumo de massa se espalharam rapidamente. De lá pra cá, esse último assumiu, cada vez mais, a forma de consumo de símbolos, isto é, ocorre de modo a produzir uma identificação com aquilo que o item de consumo representa" (SVENDSEN, 2010. p.42). Sendo assim, as identidades das marcas são apreendidas por meio de experiências dos indivíduos e uma variedade de superfícies de contato em que tais experiências se manifestam. 
Pode-se considerar então, que a identidade de uma pessoa e de uma marca pode ser percebida através de linguagens e da manipulação de signos. Especificamente em relação à marca, esses signos podem ser considerados estímulos que impulsionam pensamentos nos indivíduos. De acordo com a natureza dos signos, do indivíduo e dos pensamentos decorrentes, esse indivíduo pode vir a se aproximar da marca e encontrar nela sentido ou identificação.

“E é esta corrida para alcançar a autorrealização que parece justificar todo esse esforço em ser consumidor na sociedade pós-moderna, na qual a ilusão está em que 0 indivíduo hedônico ganhou do social coletivo" (MIRANDA, 2008. p.37). Na atual configuração social, os sujeitos inseridos no ethos moda precisam manipular adequadamente fichas simbólicas, através da posse de objetos materiais e imateriais. De tal modo, a alienação, ou desencaixe, dá-se através da oferta variada de produtos que propõem o afastamento do homem de si mesmo, tendo o espaço todo mapeado por objetos e marcas.

Considerando-se que todo o fenômeno de cultura só funciona culturalmente porque é também um fenômeno de comunicação, e considerando-se que estes fenômenos só comunicam porque se estruturam como linguagem, pode-se concluir que todo e qualquer fato cultural, toda e qualquer atividade ou prática social constituem-se como práticas significantes, isto é, práticas de produção de linguagem e de sentido. (SANTAELLA, 1994. p.5)

\section{Considerações Finais}

Se o design, como propõe Sudjic (2010, p.21) é "a linguagem com que se moldam os objetos e confeccionam as mensagens que eles carregam", cada vez mais é papel do bom designer construir mensagens sofisticadas que atrelem apelos funcionais, formais e emocionais. Cabe ao designer ser o narrador da história. 0 papel de organizador de mensagens, ou de narrador de contos, implica no potencial estratégico mercadológico que o design vem assumindo desde a década de 1960, enquanto gestor de projetos, processos e marcas.

0 desenrolar das histórias tecidas pelos designers, seja para a criação de produtos ou no investimento de ações para a construção da imagem da marca, reverberam e resultam de significações já existentes, consolidadas ou incipientes, na cultura. Cada composição gráfica para expressão da marca é um fragmento de dois códigos: um código genético e um código cultural. 0 código cultural revela, além do código genético, não apenas características de uma organização, mas as qualidades da cultura em um determinado período de tempo.

Cada vez mais a teoria do zeitgeist, que acredita na existência de um espírito do tempo que influencia as mais diversas áreas da expressão da cultura, ganha expressão. Sudjic (2010, p.35) assevera que: 
traços do mesmo código podem ser encontrados em tudo que compartilhe as mesmas raízes - uma cadeira, um carro, uma letra, até uma aeronave, sem falar num arranha-céu ou numa cidade. Até certo ponto o código é reflexo de como o objeto é feito, mas também reflete seu significado simbólico.

Acredita-se que, para o sucesso de uma marca, é necessário que seu código genético esteja em congruência com o código cultural. Pode-se afirmar que a construção de um código genético para uma marca carrega elementos, conceitos, afetividades e todo um repertório cultural contaminado de história, de memória, de passado. Ainda sim se reforça que as mensagens que uma marca deve produzir, em meio a esse acervo cultural, devem ser as mais recentes possíveis, já que um dos conceitos que atribuem significado simbólico aos produtos e marcas é a qualidade do novo.

0 significado de marca inserida no contexto cultural vai além de um simples nome ou algumas amostras de sua comunicação. É resultado de pesquisas em profundidade das versões de realidade no contexto cultural. Em um paradigma que investe cada vez mais no simbólico como moeda mercantil, a marca revela facetas diferenciais nos produtos. Ultrapassou-se a funcionalidade, a pura experimentação. Ao consumir marca vivenciamos trocas simbólicas através da cultura material, onde consumir torna-se cada vez mais etéreo. 


\section{Referências}

> ADG. ADG Brasil. Disponível em: 〈www.adg.ogr.br〉. Acesso em: 24 de out. de 2012 às $13: 46$ hs.

> DE MASI, Domênico. 0 ócio criativo. 5.ed. Rio de Janeiro: Sextante, 2000.

> DIAS, Alvaro. (Des)leituras de uma identidade visual. Dissertação de Mestrado em Ciências da Linguagem. Florianópolis: Universidade do Sul de Santa Catarina, 2006.

> HALL, Stuart. A identidade cultural na pós-modernidade. Rio de Janeiro: Dpcta,

> MIRANDA, Ana Paula de. Consumo de moda: a relação pessoa-objeto. São Paulo: Editoras das Letras e Cores, 2008.

> MOZOTTA, Brigitte Borja de. Gestão do Design. Porto Alegre: Bookman, 2011.

> PERASSI, Richard Luiz de Sousa. Apostila da Disciplina de Design e Cultura (material didático). Florianópolis: SE, 2011.

> PERASSI, Richard Luiz de Sousa. Apostila da Disciplina de Branding (material didático). Florianópolis: SE, 2010.

> RANDAZZO, Sal. A criação de mitos na publicidade. Rio de Janeiro, Rocco, 1997.

> SANTAELLA, Lucia. 0 que é semiótica. 12 ed. São Paulo: Brasiliense, 1994.

> SUDJIC, Deyan. A linguagem das coisas. Rio de Janeiro: Intrínseca, 2010.

> SVENDSEN, Lars. Moda: uma filosofia. São Paulo: Zahar, 2010.

Amanda Queiroz Campos, UFSC

amandaqc88@gmail.com

Álvaro Dias, mestre - UFSC

prof.alvarodias@gmail.com

Richard L. de Sousa Perassi, doutor - UFSC

richard.perassi@uol.com.br 